\title{
Computed Radiography in Pediatrics
}

\author{
Katsuhiko Aoki
}

Computed radiography (CR) has various advantages such as dynamic range. Diagnostic accuracy with CR using reduced radiation dose is considered comparable with that of conventional film-screen radiogra-

From the Department of Radiology, Shizuoka Children's Hospital, Shizuoka, Japan.

Address reprint requests to Katsuhiko Aoki, MD, Department of Radiology, Shizuoka Children's Hospital, 860 Unushiyama, Shizuoka 420, Japan.

Copyright (C) 1995 by W.B. Saunders Company 0897-1889/95/0801-1020\$3.00/0 phy in diagnosing apparent chest abnormalities. In addition to reducing the radiation dose, delineation of the various structures in infants can be obtained with CR using postprocessing. Even in cases involving inadequate exposure, appropriate information can be obtained by postprocessing. For these reasons, the cumulative dose of radiation exposure will be reduced. Thus, reduction of the radiation dose is the greatest advantage of using CR in pediatrics.

Copyright $\odot 1995$ by W.B. Saunders Company

KEY WORDS: computed radiography, pediatric radiology, reduced radiation exposure.
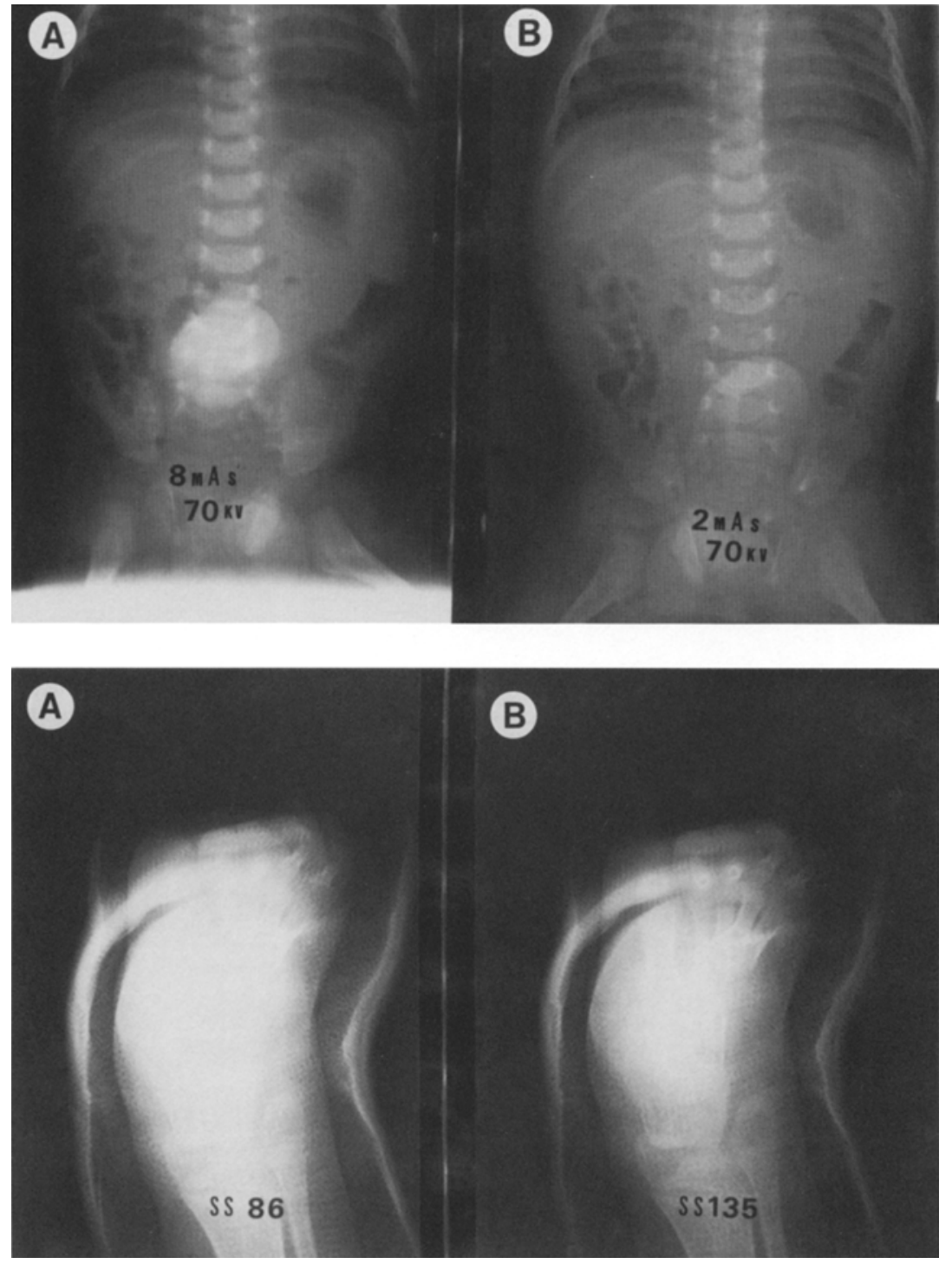

Fig 1. Conventional filmscreen abdominal radiograph at $70 \mathrm{kVp}, 8 \mathrm{mAs}$ (A) and CA image (B) at $70 \mathrm{kVp}, 2 \mathrm{mAs}$. The margins of the ribs are somewhat blurred by motion. The patient was reexamined by $C R$ immediately afterward. On the CR image, the margins of the ribs are sharp. The exposure time or radiation dose of $C R$ is one fourth that of conventional radiography.

Fig 2. CR images with portable unit after plaster casting for club foot. The initial CR image (left) is poorly exposed, and the alignment of the tarsal cannot be detected. The revised image (system sensitivity was changed from 86 to 135) shows good quality. 
$\mathbf{T}$ HE COMPUTED RADIOGRAPHY system that was provided by Fuji Photo Film Co Ltd (Tokyo, Japan) has been installed in Shizuoka Children's Hospital since November 1989. This new modality has great advantages in pediatric radiology.

\section{REDUCTION OF THE RADIATION DOSE}

The application of CR is beneficial for children, who are more sensitive to radiation hazards than adults. When a CR system is used, a reduction in radiation dose can be accomplished as follows: (1) reduction of the radiation dose per exposure; (2) reduction of a total accumulated radiation dose for each patient during his life; or (3) reduction of the total dose of radiation to the population when mass screenings are performed. Furthermore, dose reduction is performed by shortening the exposure time (mAs). This may also prevent motion artifact and avoid repeat examinations (fig 1 ).

\section{WIDE DYNAMIC RANGE}

In pediatrics, $x$-ray examinations are frequently performed in the ward using portable unit. This is a case that CR is suitable because of wide dynamic range, one of the advantages of CR. Last year, $68.3 \%$ of all in-patient plain chest radiographs were taken with the portable unit in our hospital. The films obtained with a portable unit may be of poor quality as a result of inappropriate exposure, but the computer

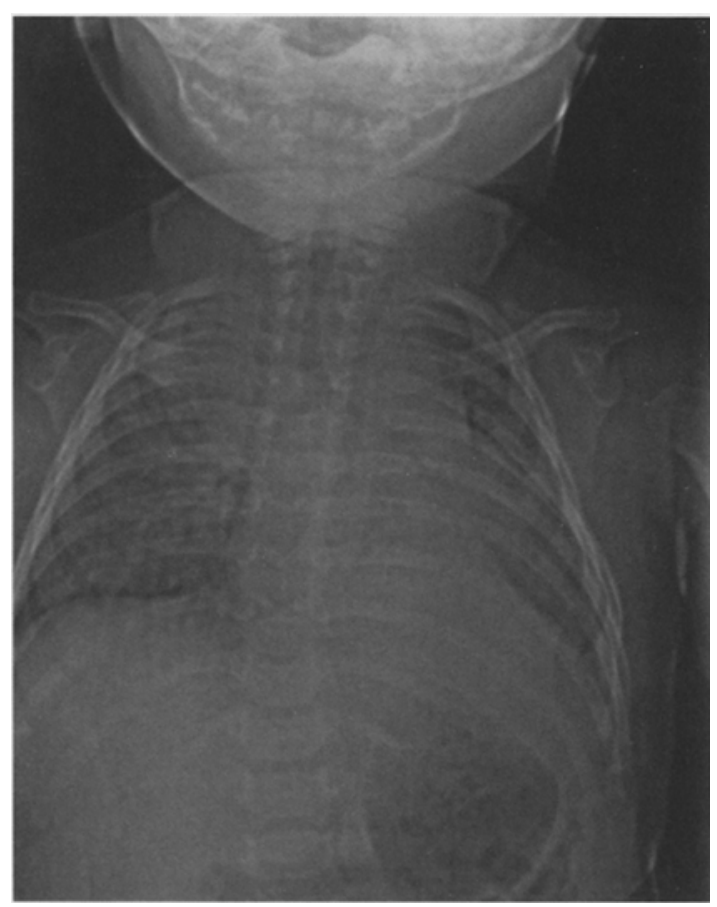

Fig 4. Chest CR image. The tracheal stenosis is easily seen on the frequency-processed image.

can process the images to enable interpretation (Fig 2).

\section{IMAGE PROCESSING}

The CR system has the ability to enhance, magnify, and invet images. This is especialiy

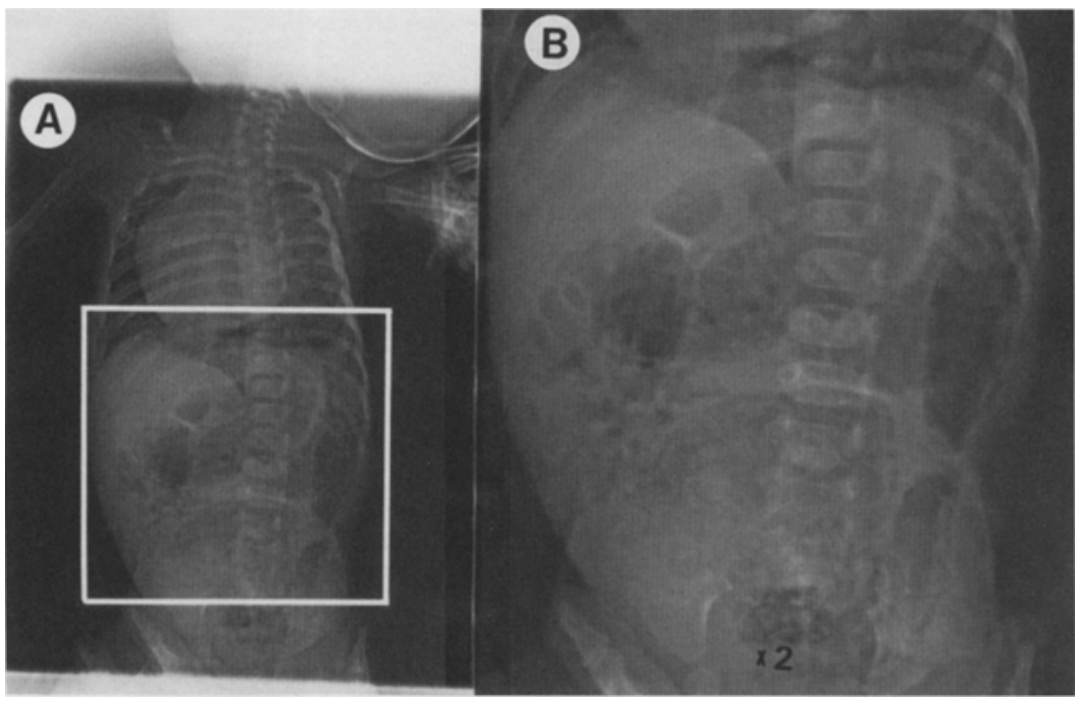

Fig 3. Abdominal CR images of necrotizing enterocolitis. On the standard-sized image (left), it is not easy to detect pnematosis intestinalis, but on the magnified image (right), the findings are easy to see (original magnification $\times 2$ ). 


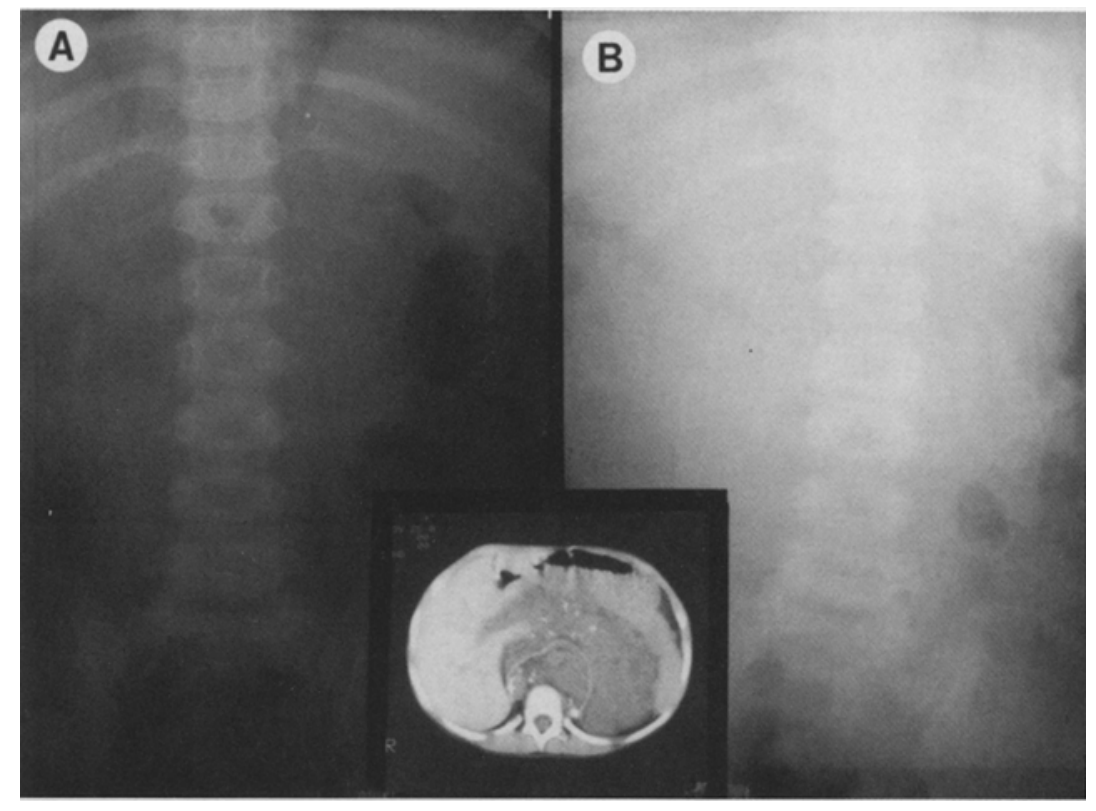

Fig 5. Abdominal radiographs in the case of neuroblastoma. The tumor calcifications are somewhat better seen on the conventional film-screen image (left) than on the CR image (right). The tumor calcification is clearly shown on the noncontrast enhanced CT image (center). suitable for pediatric radiography because the organs of young children, which are small with relatively little fat surrounding them, may be difficult to delineate (Fig 3).

\section{CLINICAL EXAMPLES OF CR IN SOME PEDIATRIC CASES}

In chest radiography, mediastinal structures are easily visualized by frequency processed images $^{2}$ (Fig 4). In the plain abdominal radiography, the abdominal viscerae are also well defined, but tumor calcifications are somewhat better seen on the conventional film-screen radiography than on the CR (Fig 5). In the urinary system, the tissue structures are clearly visible on the CR image, whereby retroperitoneal lesions are detectable easily (Fig 6). On contrast study for a low-birthweight newborn, as the dose of the contrast media that can be used is limited, a repeat contrast study must be avoided. If a poor-quality image is obtained, the computer can be used for postprocessing of the image (Fig 7).
Fig 6. A case of percutaneous nephrostomy. On abdominal CR image [left], the properitoneal fat is ill-defined \{arrow\}, suggesting an inflammatory process. The nephrostomy (right) shows leak. age of the contrast media into the periphrenic space.

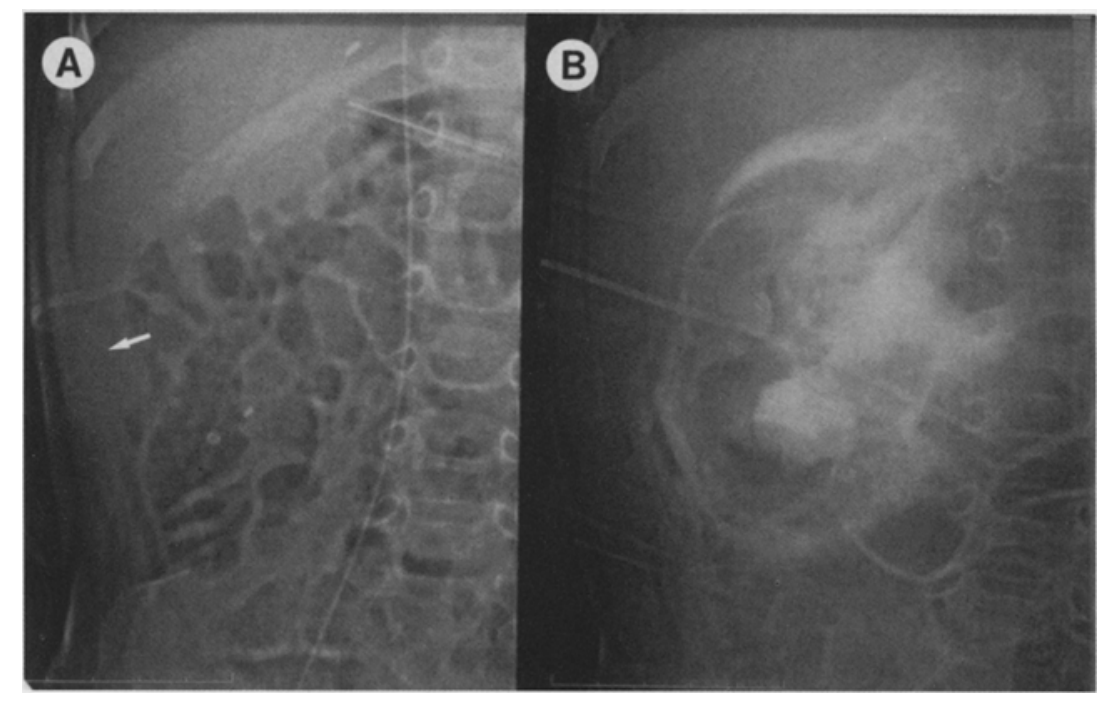




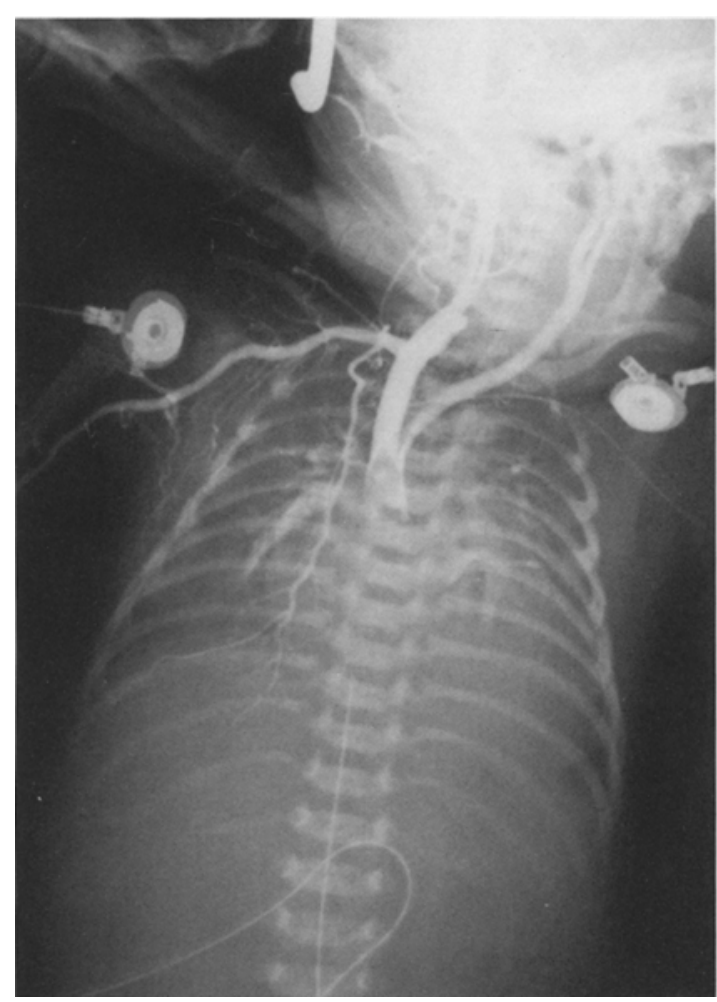

Fig 7. A one-shot contrast study via right radial artery in the case of aortic interruption. No repeated contrast media injection can be permitted for a low-birthweight newborn.

In the case of a malignant bone tumor, the destructive bony lesion is not only detectable, but the extraneous soft tissue changes are also visible on the same image (Fig 8). In the case of a soft tissue tumor, the extension of the lesion can be visualized on wide-latitude images (Fig 9).

\section{CONCLUSION}

Images can be obtained with a lower exposure dose. This reduces radiation for each exposure, for a lower total accumulative lifetime dose and for lower exposures in population during screening studies. High-quality images can be obtained, including those from portable equipment as are frequently taken in pediatrics. And lastly, image processing is available when initial films are difficult to interpret.

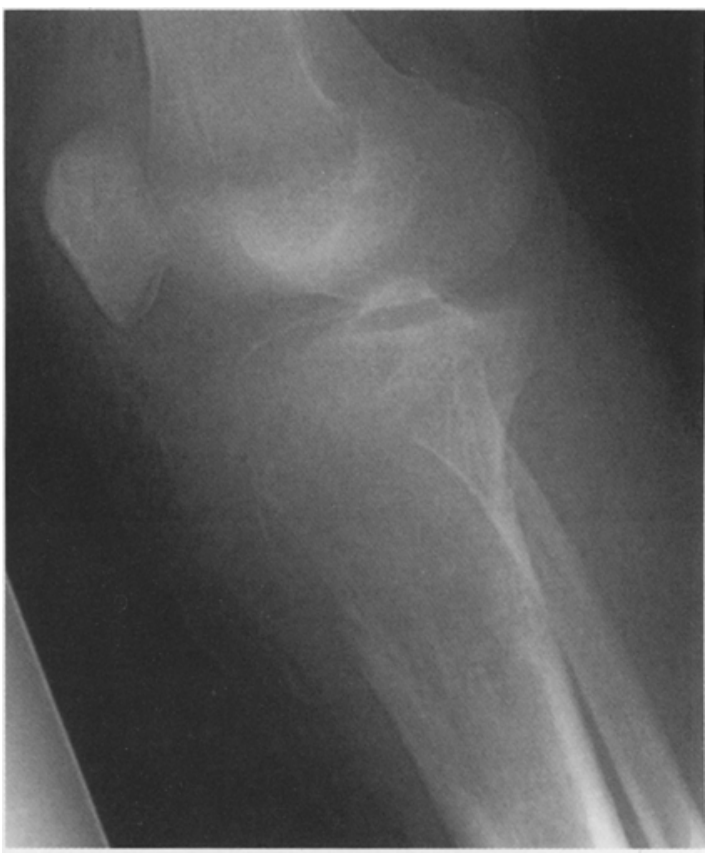

Fig 8. Lateral view of knee joint in osteogenic sarcoma. Not only destructive bony lesion, but also extraosseous soft-tissue mass is visible on a single CR image.

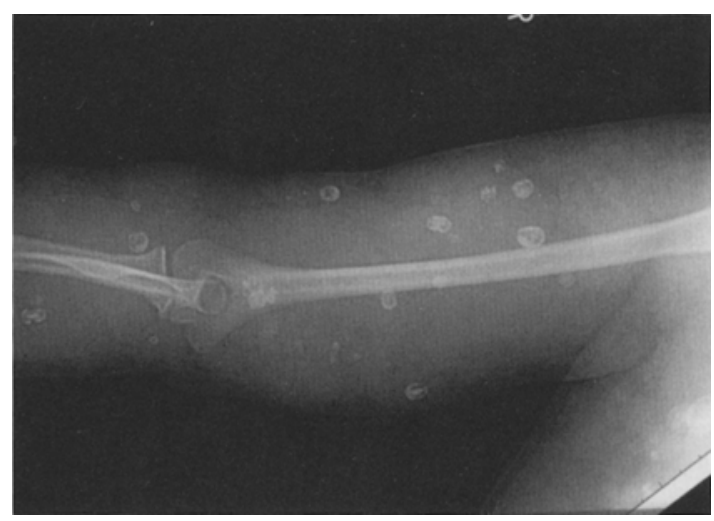

Fig 9. Extensive hemangiomatosis of the right upper extremity. Multiple phleboliths and hemangiomatosis in the subcutaneous layer are seen on the wide-latitude CR image.

\section{REFERENCES}

1. Fujiwara T, Odagiri K: CR application in children. Clin Imaging 5:74-81, 1989

2. Fujioka M: Upper airway in children: Medical application of $\mathrm{CR}$, in Tateno $\mathrm{M}$, Iinuma $\mathrm{A}$, Takano $\mathrm{M}$ (eds): Computed Radiography. New York, NY, Springer-Verlag, 1987, pp 71-76 